[Chem. Pharm. Bull.]

35(12)5004-5009(1987) $]$

\title{
Determination of Chlorpromazine, Thiamine, Lincomycin, Ofloxacin and Theophylline by Ternary Complex Formation with Eosin and Palladium(II) ${ }^{1)}$
}

\author{
Yoshikazu Fujita, Itsuo Mori, ${ }^{*}$ Kinuko Fujita, \\ YoshiHIRo NaKaHASHI and TaKeshi TANAKa \\ Osaka University of Pharmaceutical Sciences, 2-10-65, \\ Kawai, Matsubara, Osaka 580, Japan
}

(Received May 26, 1987)

\begin{abstract}
Color reactions among a drug, an organic dye and a metal ion were studied, and a simple and sensitive spectrophotometric method, without solvent extraction, has been established for the determination of some drugs by ternary complex formation with eosin and palladium(II) (probably involving an ion-association complex between $\left(\mathrm{Pd}^{\mathrm{II}}(\mathrm{drug})_{n}\right)$ cation and eosin anion). Beer's law held up to $c a .2 .0 \times 10^{-5} \mathrm{M}$ of each drug at $545 \mathrm{~nm}$ in the final volume of $10 \mathrm{ml}$, with apparent molar absorptivities of $5.7 \times 10^{4} 1 \mathrm{~mol}^{-1} \mathrm{~cm}^{-1}$ for chlorpromazine, $6.7 \times 10^{4}$ for thiamine, $5.5 \times 10^{4}$ for lincomycin, $4.0 \times 10^{4}$ for ofloxacin, and $3.5 \times 10^{4}$ for theophylline. The proposed method was applied to the determination of these drugs in pharmaceutical preparations. A fluorescence quenching method for the determination of these drugs by forming this ternary complex was also investigated for the purpose of enhancing the sensitivity of determination.
\end{abstract}

Keywords_— spectrophotometry; fluorometry; ternary complex; eosin; palladium(II); chlorpromazine; thiamine; lincomycin; ofloxacin; theophylline

Of the methods available for enhancing the sensitivity of determination of organic compounds, the ion-pair complex formation system between an organic dye and an organic compound has often been used; suitable organic dyes ${ }^{2)}$ are bromothymol blue, bromophenol blue, bromocresol green, methyl orange, tropaeolin OO, eosin, zincon, chromazurol S, tetrabromophenolphthalein ethyl ester, etc. These methods are complicated since they require an extraction procedure due to the formation of water-insoluble complexes. The addition of a surfactant or a water-micible organic solvent to avoid to any extraction procedure usually causes decomposition of the ion-pair complexes formed, and thus the organic compounds can not be determined any longer. In addition, these methods are not sensitive enough.

We have already reported ${ }^{3)}$ some simple and sensitive spectrophotometric methods, which do not require any process of solvent extraction, for the determination of various organic compounds with an organic dye and a metal ion.

In this research, color reactions of various $\cdot d r u g s$ by utilizing the ternary complex formation among an organic dye, a metal ion and an organic compound were studied in aqueous media, and then suitable conditions for the spectrophotometric determination of some drugs (chlorpromazine (CP), thiamine (TA), lincomycin (LCM), ofloxacin (OFLX) and theophylline (TP)) by using eosin and palladium (II) (Pd(II)) were established. The proposed method was applied to the assays of these drugs in pharmaceutical preparations. A fluorescence quenching method to determine these drugs was also investigated.

\section{Experimental}

Reagents and Apparatus_-Standard aqueous solutions $\left(1.0 \times 10^{-3} \mathrm{M}, \mathrm{M}=\mathrm{mol}^{-1}\right)$ of CP, TA, LCM, OFLX 
and TP were prepared by dissolving appropriate quantities of $\mathrm{CP} \cdot \mathrm{HCl}$ (Sigma Chemical Ltd.), TA $\cdot \mathrm{HCl}$ (Wako Pure Co., Ltd.), LCM $\cdot \mathrm{HCl}$ (Japan Upjohn Ltd.), OFLX (Daiichi Pharmaceutical Co., Ltd.) and TP (Tokyo Kasei Kogyo Co., Ltd.). Eosin and Pd (II) solutions were prepared as $2.0 \times 10^{-3} \mathrm{M}$ aqueous solutions, as described in the previous reports. ${ }^{3)}$ A $0.5 \%$ methylcellulose (MC) solution was prepared by dissolving MC (1500 cps, Kishida Chemical Co., Ltd.) in cold water. A buffer solution ( $\mathrm{pH} 4.3$ ) was prepared by mixing $0.2 \mathrm{M}$ acetic acid and $0.2 \mathrm{M}$ sodium acetate solutions. All other reagents and materials were of analytical grade, and were used without further purification. Deionized water was used. A Shimadzu model UV 240 spectrophotometer and a Shimadzu model RF-540 spectrofluorometer with $1.0-\mathrm{cm}$ quartz cells were used. The $\mathrm{pH}$ measurements were made with a Hitachi-Horiba F-7 AD pH meter with a combination calomel glass electrode.

Standard Procedure for the Spectrophotometry_-An aliquot of each drug solution (up to $\mathrm{ca} .2 .0 \times 10^{-5} \mathrm{M}$ ) was transferred to a $10-\mathrm{ml}$ calibrated flask. To this, $1.5 \mathrm{ml}$ of a $0.5 \% \mathrm{MC}$ solution, $3.0 \mathrm{ml}$ of the buffer solution (pH 4.3$)$, $0.75 \mathrm{ml}$ of a $2.0 \times 10^{-3} \mathrm{M}$ eosin solution and $0.75 \mathrm{ml}$ of a $2.0 \times 10^{-3} \mathrm{M} \mathrm{Pd}(\mathrm{II})$ solution were added. The mixture was diluted to $10 \mathrm{ml}$ with water, kept at $50^{\circ} \mathrm{C}$ for $30 \mathrm{~min}$, and then cooled for $5 \mathrm{~min}$ in water. The absorbance of the eosin$\mathrm{Pd}(\mathrm{II})$-drug solution (solution A) was measured at $545 \mathrm{~nm}$ against a similarly prepared eosin-Pd(II) solution (solution B).

Recommended Procedure for the Fluorometry-A sample solution containing up to $\mathrm{ca} .7 .5 \times 10^{-6} \mathrm{M}$ of each drug was placed in a $10-\mathrm{ml}$ calibrated flask. To this solution, $1.5 \mathrm{ml}$ of a $0.5 \% \mathrm{MC}$ solution, $3.0 \mathrm{ml}$ of the buffer solution, $0.5 \mathrm{ml}$ of a $2.0 \times 10^{-3} \mathrm{M}$ eosin solution and $0.5 \mathrm{ml}$ of a $2.0 \times 1.0^{-3} \mathrm{M} \mathrm{Pd}(\mathrm{II})$ solution were added. The mixture was diluted to $10 \mathrm{ml}$ with water and kept at $50^{\circ} \mathrm{C}$ for $30 \mathrm{~min}$. Solutions A and B were cooled to room temperature in water for $5 \mathrm{~min}$, then the difference of relative fluorescence intensity between solutions A and B at $545 \mathrm{~nm}$ emission wavelength with excitation at $462 \mathrm{~nm}$ was measured.

\section{Results and Discussion}

On the addition of TA to the eosin-Pd(II) solution (solution B), a distinct difference of absorbance between the eosin-Pd(II)-TA solution (solution A) and solution B was observed at around $545 \mathrm{~nm}$, and the absorbance difference of solution A against solution B was proportional to the concentration of TA. The absorbance of solution B at $545 \mathrm{~nm}$ was relatively low.

The effect of organic dyes was studied by measuring the difference of absorbance between organic dye-Pd(II)-TA or organic dye-Pd(II)-LCM and organic dye-Pd(II) solutions. Ionassociation reagents such as eosin, phloxine, fluorescein, dibromofluorescein and bromophenol blue increased the absorbance of organic dye-Pd(II) solution, whereas chelating reagents such as $o$-hydroxyhydroquinonephthalein, pyrogalloi red, zincon, chromazurol $\mathrm{S}$ and aluminon decreased its absorbance. Eosin was chosen on the basis of sensitivity.

The effect of metal ions was examined. Only Pd(II) was effective among various metal ions; Pd(II), iron(III), titanium(IV), zirconium(IV), aluminum(III), zinc(II), copper(II), manganese(II), silver(I), etc.

About 30 kinds of drugs were examined in the colored complex formation system with eosin and $\mathrm{Pd}(\mathrm{II})$. The results showed that compounds involving heterocyclic N-bases or Sbases were apt to form colored complexes. In this paper, suitable conditions for the determination of CP, TA, LCM, OFLX and TP are described.

\section{Study of the Optimum Conditions for the Spectrophotometry}

A maximum and constant absorbance of solution A against solution $\mathbf{B}$ was observed in the range of $\mathrm{pH} 3.8-4.5$ with $3.0 \mathrm{ml}$ of a $0.2 \mathrm{M}$ acetic acid $-0.2 \mathrm{M}$ sodium acetate buffer solution.

Solution A without surfactant was unstable and gave a precipitate. In order to solubilize and stabilize the colored.complex, the use of various surfactants was tried. Cationic surfactants such as cetylpyridinium chloride depressed the colored complex formation due to the formation of an ion-pair complex between eosin and the cationic surfactant. MC $(1500 \mathrm{cps})$, which is a nonionic and water-soluble polymeric surfactant, was found to be the best dispersion agent with respect to sensitivity.

The effect of the amounts of eosin and $\mathrm{Pd}(\mathrm{II})$ was examined by varying the molar ratio of 
TABle I. Sensitivities, Reproducibilities and Complex Compositions of Some Drugs in the Proposed Method

\begin{tabular}{lccc}
\hline \hline Drug & $\begin{array}{c}\varepsilon^{a)} \\
\left(\times 10^{4}\right)\end{array}$ & R.S.D. $^{b}$ & $\begin{array}{c}\text { Mole ratio } \\
(\text { Pd: eosin: drug })\end{array}$ \\
\hline CP & 5.7 & 0.5 & $1: 1: 2$ \\
TA & 6.7 & 1.0 & $1: 1: 2$ \\
LCM & 5.5 & 0.8 & $3: 3: 1$ \\
TP & 3.5 & 2.1 & $1: 1: 1$ \\
OPLX & 4.0 & 2.1 & $1: 1: 1$ \\
\hline
\end{tabular}

a) Apparent molar absorptivity. b) Relative standard deviation $(n=5)$.

eosin to $\mathrm{Pd}(\mathrm{II})$, the amounts of $\mathrm{Pd}(\mathrm{II})$ and $\mathrm{CP}$ being kept constant. A maximum absorbance was observed when the molar ratio of $\mathrm{Pd}(\mathrm{II})$ to eosin was approximately $1: 1$. Further, it was found that the eosin-to-Pd(II) ratio in the presence of a drug was $1: 1$. All further work was thus carried out with $1.5 \times 10^{-5} \mathrm{M}$ eosin and $\operatorname{Pd}(\mathrm{II})$ in the final volume, taking into consideration the determination limit of drugs.

The color development at room temperature was very slow, more than $24 \mathrm{~h}$ being required. The effects of temperature and time were examined by heating for $10-60 \mathrm{~min}$ at various temperatures $\left(40,50\right.$ and $\left.60^{\circ} \mathrm{C}\right)$; an almost constant absorbance was obtained at $50^{\circ} \mathrm{C}$ for $25-60 \mathrm{~min}$ or at $60^{\circ} \mathrm{C}$ for $20-50 \mathrm{~min}$, followed by cooling to room temperature. As both of solutions $\mathrm{A}$ and $\mathrm{B}$ on heating at $60^{\circ} \mathrm{C}$ formed jelly-like aggregates, which disappeared on cooling and agitating, the reproducibility was somewhat poor (the conditions are beyond the cloud point of $\left.\mathrm{MC}^{4}\right)$. The absorbance of solution A against solution $\mathrm{B}$ kept at $50^{\circ} \mathrm{C}$ for $30 \mathrm{~min}$ and cooled for $5 \mathrm{~min}$ in water remained constant for at least $24 \mathrm{~h}$.

\section{Calibration Curves and Nature of Ternary Complex}

Under the standard procedure, calibration curves were prepared for CP, TA, LCM, OFLX and TP. Good linear relationship was obtained in the range up to $c a .2 .0 \times 10^{-5} \mathrm{M}$ of each drug in the final volume of $10 \mathrm{ml}$. The apparent molar absorptivities $(\varepsilon)$, the relative standard deviations (R,S.D., $n=5$ ) and the compositions of the ternary complexes obtained by the molar-ratio and continuous variation methods are listed in Table I.

Next, a study to establish the character of the ternary complex was performed. The acid dissociation properties of eosin in the presence of MC were determined spectrophotometrically $^{5)}$ at an ionic strength of 0.1 at $20 \pm 0.1^{\circ} \mathrm{C}$. Eosin exists in any of the following forms, depending on the $\mathrm{pH}$ in aqueous solution:

$$
\mathrm{H}_{3} \mathrm{R}^{+} \stackrel{K_{\mathrm{a}_{1}}}{\rightleftharpoons} \mathrm{H}_{2} \mathrm{R} \stackrel{K_{\mathrm{a}_{2}}}{\rightleftharpoons} \mathrm{HR}^{-} \stackrel{K_{\mathrm{a}_{3}}}{\rightleftharpoons} \mathrm{R}^{2-}
$$

Where $\mathrm{R}$ denotes the undissociated parts of eosin. It was found that $\mathrm{p} K_{\mathrm{a} 1}, \mathrm{p} K_{\mathrm{a} 2}$ and $\mathrm{p} K_{\mathrm{a} 3}$ in the presence of MC were $-2.10,2.85$ and 4.95 , respectively, and about $80 \%$ of eosin at $\mathrm{pH}$ 4.3 was estimated $^{6)}$ to be $\mathrm{HR}^{-}$. Moreover, this ternary complex without surfactant was fairly well extracted into $n$-butanol (dielectric constant, $17.7^{77}$ ), but got an insoluble film was formed at the interface of the two phases in methyl isobutylketone (13.1). The color development was remarkably depressed by the coexistence of small amounts of methanol or cationic surfactant. On the other hand, Shcherboy et al. ${ }^{8)}$ reported a fluorometric method for the determination of $\operatorname{Pd}($ II) with eosin and 1,10-phenanthroline (phen). On the addition of phen to solution $\mathrm{B}$, the same colored complex $\left(\varepsilon \approx 3.4 \times 10^{4}\right)$ was produced. This reaction is based on the ionassociation complex formation ${ }^{9)}$ between $[\operatorname{Pd}(\mathrm{phen})]^{2+}$ as a cationic component and eosin as an anionic counter-ion. From the results, it is deduced that the ternary complex formed in this 
reaction system may be the ion-association complex between $\left(\mathrm{Pd}^{\mathrm{II}}(\mathrm{drug})_{n}\right)$ cation and eosin anion.

\section{Effect of Foreign Substances}

The effect of foreign ions and substances on the determination of LCM or CP was examined. The following ions and substances caused no interference up to at least the concentrations indicated: 100 -fold molar excess over LCM or $\mathrm{CP}$ of $\mathrm{Ca}(\mathrm{II}), \mathrm{Mg}(\mathrm{II}), \mathrm{K}(\mathrm{I})$, $\mathrm{Na}(\mathrm{I})$, fluoride, chloride, nitrate, sulfate, phosphate, glucose, lactose, succinate and urea; 10to 20 -fold molar excess of $\mathrm{Cu}(\mathrm{II}), \mathrm{Co}$ (II) and $\mathrm{Zn}$ (II). $\mathrm{Fe}(\mathrm{III})$, iodide, thiocyanate, tartrate, citrate, salicylate, ascorbate, glycine; caffeine, diphenhydramine and panthothenate interfere at 1 - to 5-fold molar excess over LCM or CP. Human albumin caused positive errors. The interference of large amounts of $\mathrm{Fe}$ (III) could be removed by addition of fluoride ion solution. To overcome the effects of small amounts of positive interfering substances such as ascorbate, caffeine, diphenhydramine and pyridoxine, a standard addition method could be used. The results are summarized in Table II.

\section{Application of the Proposed Method}

The proposed method was applied to the determination of $\mathrm{CP} \cdot \mathrm{HCl}, \mathrm{TA} \cdot \mathrm{HCl}$, $\mathrm{LCM} \cdot \mathrm{HCl}, \mathrm{OPLX}$ and TP in pharmaceutical preparations (tablet, capsule and injection). The content of a tablet or capsule was accurately weighed and ground in a mortar to a fine powder. The required amount of the powder was weighed, transferred into a $100-\mathrm{ml}$ volumetric flask, diluted to the mark with water and filtered. An injection without pretreatment was transferred into a $100-\mathrm{ml}$ volumetric flask and diluted to the mark with water. An appropriate amount of the sample solution was taken and assayed according to the standard procedure. The results obtained by the proposed method were in good agreement with those results of the other procedures, and recoveries were satisfactory (about $98-101 \%$ ). The results are presented in Table III.

\section{Study of the Fluorometry}

As the formation of this ternary complex reduced the fluorescence of solution $\mathrm{B}$, a fluorescence quenching method for the determination of these drugs was also investigated. The uncorrected fluorescence emission spectra of solutions A and B are shown in Fig. 1. On

TABLE II. Effect of Foreign Substances

\begin{tabular}{lcccc}
\hline \hline \multicolumn{1}{c}{ Substance } & Added $^{a)}$ & $\begin{array}{c}\text { Recovery of } \\
\text { LCM (\%) }\end{array}$ & Added $^{a)}$ & $\begin{array}{r}\text { Recovery of } \\
\text { CP (\%) }\end{array}$ \\
\hline Fe(III), alum & - & 100.0 & - & 100.0 \\
$\mathrm{Ca}(\mathrm{II})$, chloride & 2 & 115.6 & 2 & 127.8 \\
$\mathrm{I}^{-}$, potassium & 100 & 100.0 & 100 & 100.0 \\
$\mathrm{H}_{2}$ PO $_{4}^{-}$, potassium & 2 & 88.0 & 2 & 88.7 \\
Citric acid & 100 & 100.0 & 100 & 100.0 \\
Ascorbic acid & 2 & 86.5 & 5 & 91.0 \\
Glycine & 2 & 118.7 & 2 & 115.5 \\
Caffeine & 5 & 83.5 & 10 & 91.5 \\
Glucose & 2 & 116.3 & 2 & 127.6 \\
Pyridoxine & 100 & 100.0 & 100 & 100.0 \\
Diphenhydramine & 2 & 117.8 & 1 & 108.3 \\
Calcium pantothenate & 2 & 116.3 & 1 & 107.6 \\
Human albumin & 2 & 97.3 & 5 & 90.0 \\
\hline
\end{tabular}

LCM and CP, $1.0 \times 10^{-5} \mathrm{M}$; eosin and $\mathrm{Pd}(\mathrm{II}), 1.5 \times 10^{-4} \mathrm{M} ; \mathrm{MC}, 0.075 \%$; reference, solution $\mathrm{B}$. a) Molar ratio (substance/LCM or CP). 
Table III. Determination of Some Drugs in Pharmaceutical Preparations

\begin{tabular}{lcccc}
\hline \hline \multirow{2}{*}{ Sample } & \multicolumn{3}{c}{ Content $(\mathrm{mg})^{a, b)}$} & \multicolumn{2}{c}{$\begin{array}{c}\text { Recovery }^{b)} \\
(\%)\end{array}$} \\
\cline { 2 - 4 } & Nominal amount & Present method & Other method & \\
\hline CP·HCl tablet & 10.0 & 9.90 & $9.89^{d)}$ & 100.8 \\
TA· HCl injection & 1.0 & 1.02 & $1.01^{e)}$ & 100.5 \\
LCM capsule & 250.0 & 253.4 & & 99.1 \\
OFLX tablet & 100.0 & 103.5 & $102.8^{f)}$ & 99.9 \\
TP injection & 201.3 & 195.7 & $197.4^{e)}$ & 98.4 \\
\hline
\end{tabular}

a) Drug content, mg per 1 tablet, capsule or injection. b) Mean of 5 determinations. c) As aminophylline injection. d) Qnph-Pd(II) method, ref. 10). e) JPX method, ref. 11). f) UV method, ref. 11).

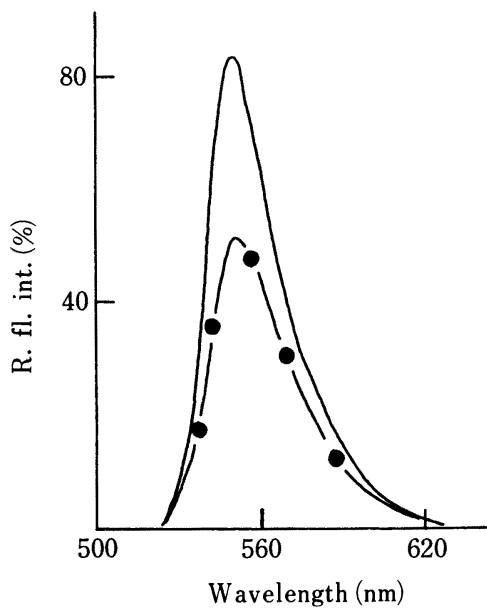

Fig. 1. Emission Spectra of Eosin-Pd(II) and Eosin-Pd(II)-CP Solutions under the Recommented Conditions

$\mathrm{CP}, 7.5 \times 10^{-6} \mathrm{M}$; eosin and $\mathrm{Pd}(\mathrm{II}), 1.0 \times 10^{-4} \mathrm{M}$; $\mathrm{MC}, 0.075 \% ; \mathrm{pH}, 4.3 ;$ excitation wavelength, $462 \mathrm{~nm}$. - - - CP-eosin-Pd(II); — , eosin-Pd(II).

the addition of CP to solution B, the relative fluorescence intensity (R. fl. int.) of solution B fell significantly, and the magnitude of the decrease was proportional to the concentration of CP.

In the development of the recommended procedure for the fluorometry, only the amounts of eosin and Pd(II) were studied, and the same conditions as for spectrophotometry were adopted for other reaction variables. The optimal amounts of eosin and $\mathrm{Pd}(\mathrm{II})$ were $1.0 \times 10^{-4} \mathrm{M}$ in the final volume of $10 \mathrm{ml}$. The calibration curves were linear in the range up to ca. $7.5 \times 10^{-6} \mathrm{M}$ of these drugs. The quenching effects decreased in the order TA $>\mathrm{CP}$, LCM $>$ TP $>$ OFLX.

In conclusion, color reactions among various drugs, eosin and $\mathrm{Pd}(\mathrm{II})$ were examined, and spectrophotometric and fluorometric determinations of some drugs (CP, TA, LCM, OFLX and TP) were established by using ternary complex formation. The ternary complex formed in this reaction system was regarded as the ion-association complex between $\left(\mathrm{Pd}^{\mathrm{II}}(\mathrm{drug})_{n}\right)$ cation and eosin anion. Compared with the conventional methods using organic dyes, ${ }^{2,12)}$ or metal ions ${ }^{13)}$ alone, the present method, which does not require an extraction procedure, has the advantages of simplicity, sensitivity and reproducibility. The present method should be useful and convenient for the simple determination and detection of various drugs for quality control and /or for screening tests, as well as for assay of pharmaceutical preparations. 
$\mathrm{LCM} \cdot \mathrm{HCl}$ and $\mathrm{OFLX}$, respectively.

\section{References and Notes}

1) This paper is Part LXIII of a series entitled "Application of Xanthene Derivatives for Analytical Chemistry," Part LXII: I. Mori, Y. Fujita, K. Fujita, Y. Koshiyama and Y. Nakahashi, Anal. Lett., accepted (1987). This work was presented at 106th and 107th Annual Meetings of the Pharmaceutical Society of Japan in Chiba, April 1986 and in Kyoto, April 1987.

2) a) M. Pesez and J. Bortos, "Colorimetric and Fluorimetric Analysis of Organic Compounds and Drugs," Marcel Dekker, Inc., New York, 1974; b) The Japan Society for Analytical Chemistry, "Bunseki Kagaku Binran," Maruzen Ltd., Tokyo, 1976; c) T. Inoue, "Iyakuhin Seizai No Bunseki," Chizinshoin, Ltd., Tokyo, 1978; d) T. Sakaguchi, "Yakuhin Bunseki Kagaku," Nankodo, Tokyo, 1978; e) W. Sadée and G. C. M. Beelen (M. Saito and Z. Tamura), "Drug Level Monitoring," Hirokawa Shoten, Tokyo, 1982; f) T. Sakai, Dojin News, 30, 1 (1984); g) T. Mitsui, Bunseki, 1985, 103.

3) a) Y. Fujita, I. Mori, S. Kitano, H. Kawabe and Y. Kamada, Bull. Chem. Soc. Jpn., 57, 1828 (1984); b) I. Mori, Y. Fujita, H. Kawabe and K. Fujita, Bunseki Kagaku, 34, 648 (1985); c) I. Mori, Y. Fujita, H. Kawabe, K. Fujita, T. Tanaka and A. Kishimoto, Analyst (London), 111, 1409 (1986); d) I. Mori, Y. Fujita and K. Sakaguchi, Bunseki Kagaku, 30, 2599 (1982).

4) A. Kitahara, Y. Tamai, S. Hayano and I. Hara, "Surface Active Agents," Kodansha Scientific, Tokyo, 1981.

5) a) A. Albert and E. P. Sejesnt (T. Matsuura), "The Ionic Constants," Maruzen Co., Tokyo (1963); b) M. Shibata, M. Nakamizo and H. Kakiyama, Nippon Kagaku Kaishi, 1972, 681.

6) H. Freiser and Q. Fernando (T. Fujinaga and E. Sekido), "Ionic Equilibria in Analytical Chemistry," Kagakudojin Ltd., Tokyo, 1977.

7) The Society of Synthetic Organic Chemistry, Japan, "The Pocketbook of Solvents," Ohme-sha, Tokyo, 1984.

8) D. P. Shcherbov, D. N. Lisitsina and I. D. Vredenskaya, Org. Reagently Anal. Khim., Tezisy Dokl. Veses. Konf., 4th, 2, 129 (1976) [Chem. Abstr., 88, 15447s (1978)].

9) P. R. Haddad, Talanta, 24, 1 (1977).

10) I. Mori, Y. Fujita and S. Kitano, Bunseki Kagaku, 32, E1 (1983).

11) "Commentary of the Japanese Pharmacopoeia, Ed. X," Nankodo, Tokyo, 1981.

12) a) J. Lelijveld and H. Kortmann, Bull. World Health, 42, 447 (1970); b) L. A. Roberts, J. Pharm. Sci., 58, 1015 (1969); c) S. Ogawa, M. Morita, K. Nishiura and K. Fujisawa, Yakugaku Zasshi, 85, 650 (1965); d) U. R. Cieri, J. Assoc. Off. Anal. Chem., 61, 937 (1978); e) A. I. Zhebentyaev, Khim.-Farm. Zh., 19, 111 (1985) [Chem. Abstr., 102, 13791 (1986)].

13) a) M. Sawada, I. Motoyama, S. Yamada and Y. Kanaya, Bunseki Kagaku, 35, T16 (1986); b) S. Tanabe and H. Taniguchi, Bunseki, 1985, 879. 